\title{
Development of planar microwave moisture sensors for hevea rubber latex and oil palm fruits
}

\begin{abstract}
A review of the several moisture sensors using planar structures such as microstrip, conductor-backed coplanar waveguide $(\mathrm{CBCPW})$ and microstrip antenna is described. These sensors are used for determination of moisture content in hevea rubber latex and oil palm fruit. This study includes the state of the art of sensor design by which the dielectric constant and dielectric loss of the hevea latex and oil palm are taking into consideration. A prototype developed known as microwave reflection type latexometer is able to measure the moisture content of hevea latex with the accuracy of less than $1 \%$ and suitable to be used at latex collecting center and latex dipping industries for process control. A close relationship has been found between insertion loss and moisture content in the mesocarp of oil palm fruit for the CBCPW sensor. This relationship will give the possibility of using this sensor to gauge fruit ripeness or oil content in the mesocarp.
\end{abstract}

Keyword: Latexometer; Moisture content; Moisture sensor 